\title{
Deep brain stimulation for obesity: rationale and approach to trial design
}

\author{
Allen L. Ho, MD, ${ }^{1}$ Eric S. Sussman, MD, ${ }^{1}$ Arjun V. Pendharkar, MD, ${ }^{1}$ Dan E. Azagury, MD, ${ }^{2}$ \\ Cara Bohon, PhD, ${ }^{3}$ and Casey H. Halpern, MD ${ }^{1,3}$
}

\begin{abstract}
${ }^{1}$ Departments of Neurosurgery, ${ }^{2}$ General Surgery, and ${ }^{3}$ Psychiatry and Behavioral Sciences, Stanford University School of Medicine, Stanford, California
\end{abstract}

\begin{abstract}
Obesity is one of the most serious public health concerns in the US. While bariatric surgery has been shown to be successful for treatment of morbid obesity for those who have undergone unsuccessful behavioral modification, its associated risks and rates of relapse are not insignificant. There exists a neurological basis for the binge-like feeding behavior observed in morbid obesity that is believed to be due to dysregulation of the reward circuitry. The authors present a review of the evidence of the neuroanatomical basis for obesity, the potential neural targets for deep brain stimulation (DBS), as well as a rationale for DBS and future trial design. Identification of an appropriate patient population that would most likely benefit from this type of therapy is essential. There are also significant cost and ethical considerations for such a neuromodulatory intervention designed to alter maladaptive behavior. Finally, the authors present a consolidated set of inclusion criteria and study end points that should serve as the basis for any trial of DBS for obesity.
\end{abstract}

http://thejns.org/doi/abs/10.3171/2015.3.FOCUS1538

KEY WORDS deep brain stimulation; obesity; lateral hypothalamus; nucleus accumbens; Prader-Willi syndrome

$\mathrm{O}$ BESITY is defined as a body mass index (BMI) greater than $30 \mathrm{~kg} / \mathrm{m}^{2}$. Recent estimates suggest that the prevalence of obesity in the US is greater than $35 \%,{ }^{19}$ with more than 500 million obese individuals worldwide. ${ }^{86}$ Obesity has been linked to an increased risk of hypertension, hyperlipidemia, Type 2 diabetes, stroke, coronary artery disease, and a variety of cancers. ${ }^{9,31}$ Furthermore, health care expenditures in obese individuals are as much as $45 \%$ higher than those in lean individuals, and economic-based models have estimated that health care costs related to obesity total $\$ 75$ billion per year in the US alone. ${ }^{34,94}$ Based on these data, obesity is one of the most pressing public health concerns.

The standard of care, first-line treatment for obesity is lifestyle modification. ${ }^{40}$ While dietary treatment can be effective in the immediate short term, the vast majority of patients fail to achieve sustained, long-term weight loss. ${ }^{2}$ The success rate of dietary treatment is increased somewhat when combined with adjuvant group therapy, behavior modification, and/or active follow-up. However, the majority of patients ultimately relapse after an initial period of weight loss. ${ }^{2}$ Bariatric surgery is indicated in patients with BMIs greater than $40 \mathrm{~kg} / \mathrm{m}^{2}$ (or $>35 \mathrm{~kg} / \mathrm{m}^{2}$ in the presence of obesity-related comorbidities) who have undergone unsuccessful nonsurgical treatment. ${ }^{18}$ These procedures have been found to be superior to behavioral modification alone,$^{13}$ and thus the number of bariatric procedures performed in the US has increased 10-fold over the past two decades. ${ }^{50}$ Bariatric surgery is one of the only effective treatments for long-term weight loss in morbid obesity. ${ }^{14}$ As a result, there has been an increasing demand for these surgical procedures. Failure of bariatric surgery is most often defined as less than $50 \%$ of excess weight loss at 18 months after the operation, with or without a

ABBREVIATIONS BMI = body mass index; DBS = deep brain stimulation; DSM = Diagnostic and Statistical Manual of Mental Disorders; $\mathrm{LH}=$ lateral hypothalamus; NAC = nucleus accumbens; $\mathrm{OCD}=$ obsessive-compulsive disorder; $\mathrm{PD}=$ Parkinson's disease; $\mathrm{PWS}=$ Prader-Willi syndrome; $\mathrm{QALY}=$ quality-adjusted life year; $\mathrm{VMH}=$ ventromedial hypothalamus; YFAS = Yale Food Addiction Scale.

SUBMITTED January 31, 2015. ACCEPTED March 26, 2015.

INCLUDE WHEN CITING DOI: 10.3171/2015.3.FOCUS1538.

DISCLOSURE The authors report no conflict of interest concerning the materials or methods used in this study or the findings specified in this paper. 
BMI greater than $35 \mathrm{~m} / \mathrm{kg}^{2} .^{51}$ Nonetheless, the rates of both short-term and long-term morbidity of bariatric surgery are not insignificant. ${ }^{21,74}$ While reported failure rates are highly variable in the literature and further depend on patient selection, degree of obesity, and surgical technique, ${ }^{1,12}$ relapse of metabolic syndrome and weight regain occur in as many as $35 \%$ of surgically treated patients at long-term follow-up. ${ }^{28}$

\section{Radiological Evidence}

Both the hypothalamus and the nucleus accumbens (NAc), two brain regions with known interconnections, have been implicated in imaging studies of obese humans. ${ }^{32}$ Sweet tastes such as glucose, sucrose, and other palatable tastes, as well as images of calorically dense food, induce abnormal responses in the NAc and hypothalamus in obese patients compared with lean controls. ${ }^{30,52,78}$ Moreover, the serotonin noradrenaline reuptake inhibitor sibutramine results in attenuated hypothalamic response to high-calorie food images, and this attenuation correlates with the drug's impact on weight and eating behavior in obese patients. Additionally, satiety after a meal attenuated the NAc response to high-calorie food images, which also correlated with eating behavior. ${ }^{20}$ Thus, change in the activity of these regions is linked to change in behavior, making them a promising target for intervention.

Murdaugh and colleagues found that a greater NAc response to high-calorie food images predicted poorer treatment response in obese patients undergoing behavioral weight-loss treatment. ${ }^{60}$ One study examining brain function in patients receiving bariatric surgery found that $a b-$ normalities in hypothalamic response to food images present in obese patients were not found more than 1 year after Roux-en-Y surgery. ${ }^{22}$ Furthermore, reduced NAc response to high-calorie food images was associated with reduced palatability and appeal of high-calorie foods and healthier eating behaviors among patients after Roux-en-Y surgery. ${ }^{72}$ Taken together, these findings further suggest these regions as promising targets for deep brain stimulation (DBS) to treat obesity, as their dysfunction appears directly associated with food stimuli and response to treatment.

\section{Deep Brain Stimulation Targets for Obesity}

Several potential DBS targets for obesity have already been identified through anatomical investigation of the appetite and reward circuitry of the brain, and studied in animal and human neuroimaging studies. Within the hypothalamus, the lateral hypothalamus (LH) and ventromedial hypothalamus (VMH) have long been recognized as the feeding and satiety centers of the brain, respectively. Functional MRI studies have demonstrated the complementary actions of these regions in perpetuating obesity in humans. ${ }^{24,80}$ Additionally, studies of the behavioral and psychiatric pathophysiology of morbid obesity have also identified altered reward circuitry in the brain that may play a role in food craving, which is commonly observed in these patients. ${ }^{41,44}$ Feelings of craving, reward anticipation, and reward-driven consumption all involve neural circuitry between the prefrontal cortex, which houses the inhibitory control regions, and the striatum, within which the NAc has traditionally played a prominent role in promoting reward-driven behavior. ${ }^{77,85}$ (Fig. 1)

In animal models, lesioning studies of the LH have revealed weight loss, and bilateral DBS in rats produced a significant weight differential compared with nonstimulated controls. ${ }^{68}$ A recent pilot study of DBS of the LH in 3 morbidly obese patients who had previously failed gastric bypass surgery was completed. While the study was designed to assess safety and not efficacy of DBS for obesity, stimulation parameters of the LH were optimized to induce a sustained increase in resting metabolism with stimulation, after which weight loss was observed, and no detrimental psychiatric symptoms were detected. ${ }^{90}$ In a similar fashion, lesions to the VMH have led to weight gain, increased adipose tissue, and hyperinsulinemia in animal models, with similar effects observed with high-frequency DBS in both murine and primate models. ${ }^{5,46}$ Low-frequency stimulation of this focus appeared to inhibit feeding behavior and increase weight loss in a wide variety of animal models, including in a recent study in primates in which Torres and colleagues proposed an intraventricular "floating" electrode inserted in the third ventricle contiguous to the VMH. Stimulation delivered to the VMH has been shown to evoke emotional panic attack-like behavior with autonomic disturbances in both animals and humans, which may preclude its suitability as a human DBS target for obesity. ${ }^{71,92}$ Nevertheless, VMH target refinement is already underway in some centers. Finally, lesioning studies involving the NAc have led to promising results in animal studies with elimination of food-hoarding behavior and significant weight loss. ${ }^{43}$ Furthermore, proof-of-concept DBS studies of the NAc specifically aimed at examining its effects on feeding behavior found a significant decrease in binge-eating behavior, as well as decreased caloric intake and sustained weight loss in obese mice. These authors also found that these stimulatory effects involved D2 receptors..$^{32}$ Moreover, the NAc is a well-validated DBS target with a good safety profile that has been exploited for treatment of such processes such as treatment-refractory depression, obsessive-compulsive disorder (OCD), and alcoholism. ${ }^{27,58,70}$ Given the link between obesity and the mesolimbic reward circuitry, further studies targeting the NAc with DBS, specifically for treatment-refractory obesity, should be considered promising.

\section{Cost and Ethical Considerations of DBS Cost Considerations}

In our current health care delivery paradigm, costs must be included in the consideration of any novel treatment modality. In evaluating the fiscal efficacy of DBS, it is reasonable to examine data comparing DBS to medical management of Parkinson's disease (PD). Several studies have demonstrated the economic superiority of DBS over medical management in PD.

In terms of absolute costs, most recent cost estimates based on the Department of Veterans Affairs and Medicare databases are approximately $\$ 17,000-65,000$ for initial DBS surgery, with up to an additional $\$ 17,000$ in annual costs for the first 3 years. However, these data were extracted for patients with PD and encompass condition- 


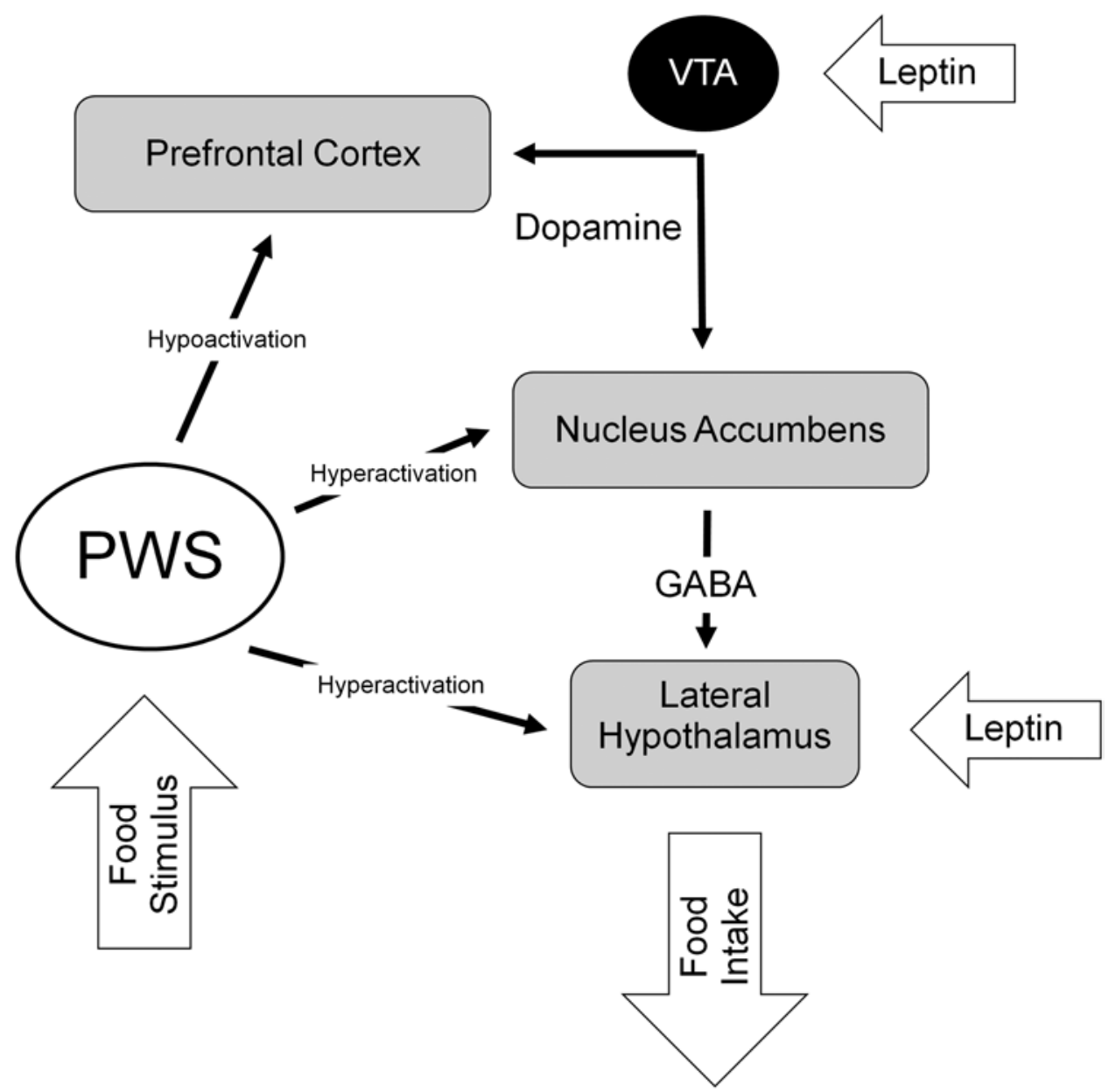

FIG. 1. Schematic diagram depicting the DBS targets for obesity and their role in the homeostatic pathway of energy balance in normal and PWS physiology. The cortical inhibitory control regions are located in the prefrontal cortex (PFC), and the subcortical reward circuitry in the nucleus accumbens (NAc), and lateral hypothalamus (LH). The LH is responsible for providing anabolic feedback onto the autonomic nervous system effectors. The NAc is the center of the reward pathway in the brain, integrating inputs from various higher cortical brain areas and the limbic system to reinforce certain beneficial behaviors, such as feeding. Integration of the reward pathways with feeding behavior begins with dopamine release from the ventral tegmental area (VTA) neurons that project onto the NAc. Within the NAc, there are GABAergic neurons that project to the $\mathrm{LH}$, which then contains neurons that drive food intake. These nuclei also respond to various hormonal peptides such as leptin, providing one of the many links between food intake and energy metabolism in the brain. In Prader-Willi syndrome (PWS), the normal cortical inhibitory control and subcortical reward circuitry are disrupted in response to food stimuli with hypoactivation of the PFC and hyperactivation of the NAc and LH compared with healthy individuals. GABA $=\gamma$-aminobutyric acid. Modified with permission from Ho et al: Cureus 7:e259, 2015. ${ }^{36}$

specific costs as well.75,79 Tomaszewski and Holloway reported that DBS in PD becomes cost effective if quality of life is improved by $18 \%$ compared with best medical management. ${ }^{82}$ Meissner et al. retrospectively studied treatment costs in DBS in PD versus medical management. ${ }^{55}$ They reported an increase in costs by $32 \%$ in the first year but a decrease by $54 \%$ in the second year. They further reported a decrease in overall medication expenses and improved efficacy in patients undergoing DBS.

In contrast, in a head-to-head study of more than 3600 bariatric surgery patients and comorbidity-matched, bariatric-surgery eligible controls, initial costs associated with laparoscopic bariatric surgery were estimated at $\$ 30,000$, but postprocedure costs savings began to accrue as soon as 3 months after the operation. The initial investment costs for the procedure were returned within 2 years, and were mainly associated with a decrease in health care utilization from obesity-related comorbidities. In addition, savings rates in the bariatric surgery cohort compared with controls increased to more than $\$ 900$ per month 1 year after surgery. This analysis did not include additional quality of life and length of life benefits, nor did it include cost benefits associated with decreased disability and unemployment. ${ }^{15}$ A separate study conducting an incremental cost-effectiveness analysis for bariatric surgery found that laparoscopic bariatric surgery was highly effective, with an associated cost of slightly more than $\$ 6000$ for each quality-adjusted life year (QALY) gained. This favorable cost-effectiveness result was maintained even in complete weight regain scenarios, with an incremental increase to $\$ 24,000$ for each QALY gained. ${ }^{89}$ In considering DBS as an adjunct treatment following bariatric surgery failure, 
there are clear cost gains to be achieved as long as similar and more enduring weight-loss results are achieved. However, given the higher surgical costs associated with DBS, there will likely be a longer interval to return on investment, as well as higher costs for each QALY gained compared with bariatric surgery.

With only a few reports of DBS in obesity there are no similar studies of actual cost effectiveness. Pisapia et al. conducted a decision analysis comparing the two major surgical options for obesity: laparoscopic Roux-en-Y gastric bypass and laparoscopic adjustable gastric banding. ${ }^{65}$ Laparoscopic banding was found to not be effective at achieving successful weight loss (defined as at least $45 \%$ of excess weight), and the complication rates for gastric bypass surgery (33\%) far exceeded those of DBS (19\%). These reports characterize DBS in obesity as a promising therapeutic avenue from an economic standpoint. With lower complication rates compared with bariatric surgery, targeted neuromodulation could decrease long-term costs in the morbidly obese patient population, especially in patients who have already failed bariatric surgery.

\section{Ethical Considerations}

As indications for neuromodulation continue to expand, there will be an ongoing debate on the ethics of intervention. The neural circuitry of obesity overlaps with that of addiction, and this may raise concerns of patient autonomy in the context of behavioral alteration. ${ }^{10}$ Specifically, targeting the NAc may lead to alterations in reward pathways or withdrawal. A patient's ability to experience normal pleasure may also be diminished or perturbed. The ethical argument is similar to the one for OCD in which benefit-harm ethical arguments favor DBS in patients with high-level decisional capacity. ${ }^{26}$ Moreover, autonomy may be fundamentally inadequate in individuals suffering from disorders of the reward circuitry, requiring experience-based paternalism on the part of doctors. ${ }^{11}$

An alternative perspective for patient autonomy suggests that neuromodulation may actually restore patient capacity to make choices. For example, Uusitalo argues that there is a distinction between difficulty and freedom in the ability of a patient to make a choice. Using the example of cravings in addiction, she eloquently highlights the possibility that DBS may reduce the difficulty in controlling cravings but, importantly, will not change a patient's freedom to continue addictive behaviors. ${ }^{83}$ Müller et al. has gone further to characterize DBS as actually granting "full autonomy" to the patient. ${ }^{59}$

The ethical underpinnings of DBS treatment for obesity will be further challenged in the clinical-trial phase. Several key factors must be clarified prior to enrollment, including trial design, informed consent, and a greater discussion on the concept that DBS treatment would be a threat to patient identity. ${ }^{64}$ As such, we advocate for a multidisciplinary team of surgeons, endocrinologists, obesity specialists, neuropsychiatrists, and ethicists to provide longitudinal guidance for delivering ethical and high-level care. We believe that in an appropriately selected population of patients who are refractory to medical and surgical management of morbid obesity, there is a role for DBS. There must be stringent inclusion criteria, informed consent, and clinical equipoise in conducting clinical trials. ${ }^{29}$

\section{Target Patient Population}

A safety and feasibility trial of DBS for obesity in humans should involve those patients who have undergone unsuccessful bariatric surgery (specifically gastric bypass) due to persistent binge-eating behavior. Predictors of bariatric surgical failure have been studied extensively and include age, sex, preoperative BMI, substance abuse, compliance with follow-up appointments, eating habits, physical activity, and psychiatric status. ${ }^{89}$ With respect to the latter, there is a growing body of evidence that patients with mood or anxiety disorders have higher failure rates after bariatric surgery..$^{16}$ Furthermore, there is a high prevalence of "loss of control" or binge eating in those individuals who regain weight. Interestingly, bariatric surgery has been repeatedly shown to improve binge-eating postoperatively. ${ }^{53,87}$ However, at 2 years after surgery, Sallet et al. noted that the association between presurgery binge eating status and higher postsurgery weight regain are most clear. ${ }^{66}$ The question remains whether ongoing maladaptive eating behaviors such as binge eating are critical factors in patients who fail bariatric surgery. ${ }^{23}$ This would be the treatment-resistant population in which we could target DBS as a multimodality treatment for weight loss.

Demonstration of treatment resistance is essential for all potential DBS trial candidates. ${ }^{25,93}$ However, for obesity, identification of a particular etiology of treatment failure is also crucial, given that DBS treatment of obesity would occur via modulation of specific neural pathways (such as the reward circuitry). The Yale Food Addiction Scale (YFAS) is the most widely used and accepted tool to measure food addiction (Table 1). ${ }^{23}$ It is based on the substance use disorder criteria in the Diagnostic and Statistical Manual of Mental Disorders-Fifth Edition (DSM-V), and is similar to other compulsive activity scales. ${ }^{38}$ There is increasing evidence in the literature to suggest that overeating may be a behavioral addiction similar to substance abuse that shares similar behavioral and neurobiological factors. ${ }^{84,95}$ Furthermore, there is evidence that scores on the YFAS are associated with brain response to anticipation of taste reward, although its relation to hypothalamic and NAc function has not yet been examined. ${ }^{24}$ In addition to weight regain, postbariatric surgery patients are at increased risk for developing alcohol and substance abuse disorders ${ }^{45,68}$ that likely represent an "addiction transfer." 91 The YFAS has been validated as predictive of continued emotional and binge-eating behavior following bariatric surgery. ${ }^{13}$ Furthermore, as noted above, the presence of binge-eating behavior after bariatric surgery is clearly associated with less weight loss and more weight regain. ${ }^{53}$ Therefore, postbariatric surgery evaluation of food addiction behavior via the YFAS may aid in identifying a subpopulation of patients who had unsuccessful bariatric surgery that would most benefit from DBS of the NAc, given the addiction and substance-abuse nature of their disorder.

External eating (sensitivity to external food cues) is associated with higher food addiction scores and decreases in weight loss after bariatric surgery ${ }^{63}$ and may be another measure to target in DBS trials for obesity. Passamonti and colleagues found that external eating scores modulated the connectivity between the ventral striatum and amygdala while viewing appetizing food images, suggesting an 
TABLE 1. Components and scoring of the YFAS*

\begin{tabular}{|c|c|c|}
\hline Substance-Dependence Symptom from DSM-IV $\dagger$ & No. of Questions $\ddagger$ & Normative \% \\
\hline Substance taken in larger amount and for longer period than intended & 3 & 21.7 \\
\hline Persistent desire or repeated unsuccessful attempt to quit & 4 & 71.3 \\
\hline Much time/activity to obtain, use, recover & 3 & 24 \\
\hline Important social, occupational, or recreational activities given up or reduced & 4 & 10.3 \\
\hline $\begin{array}{l}\text { Use continues despite knowledge of adverse consequences (e.g., failure to fulfill role obliga- } \\
\text { tion, use when physically hazardous) }\end{array}$ & 1 & 28.3 \\
\hline Tolerance (marked increase in amount; marked decrease in effect) & 2 & 13.5 \\
\hline Characteristic withdrawal symptoms; substance taken to relieve withdrawal & 3 & 16.3 \\
\hline Use causes clinically significant impairment & 2 & 14 \\
\hline \multicolumn{3}{|c|}{$\begin{array}{l}\text { * Adapted from Gearhardt AN, Corbin WR, Brownell KD. Yale Food Addiction Scale (YFAS). Measurement Instrument Database for the Social } \\
\text { Sciences, 2012. Retrieved from www.midss.ie. Copyright: CC BY-NC } 3.0 \text { (http://creativecommons.org/licenses/by-nc/3.0/). } \\
\text { † Number of questions within the YFAS addressing each symptom of substance dependence as defined by the DSM-IV, and the percentage of } \\
\text { normal patients with each symptom (normative \%). } \\
\text { † The YFAS scoring algorithm with a median symptom count was as follows: if scoring for a specific criterion is } \geq 1 \text {, then the criterion for } \\
\text { that symptom is met; substance dependence is considered when } \geq 3 \text { symptom criteria are met. The normative percentage of normal patients } \\
\text { surveyed with the scale that met YFAS criteria for substance dependence was } 11.6 \% \text {. }\end{array}$} \\
\hline
\end{tabular}

association between these brain processes and sensitivity to food cues, which could be improved through DBS. ${ }^{62}$

\section{Inclusion Criteria}

Determination of appropriate inclusion criteria for a DBS obesity trial would be similar to previous studies published to date for other DBS trials for psychiatric indications. ${ }^{3,17,57}$ In most other disease trials for DBS, surgery was offered to patients with severe symptoms in whom medical therapy had failed, and who did not have any other major contraindications to DBS. ${ }^{47}$ Trial design would largely depend on the proposed DBS target, but the need for a traditional Phase I clinical trial may be obviated by the fact that a reasonable safety profile has been largely established by previous pilot trials/studies of both $\mathrm{LH}^{90}$ and $\mathrm{NAc}^{3,17}$ targets. Thus, proof-of-concept and efficacy studies would be the next logical step. Patients with general contraindications to DBS should be excluded (Table 2). DBS could be offered to adult patients with morbid obesity (BMI $>40 \mathrm{~kg} / \mathrm{m}^{2}$, or $35 \mathrm{~kg} / \mathrm{m}^{2}$ with comorbidities) in whom medical therapy and bariatric surgery have failed, with greater consideration given to patients with obesity-related comorbidities such as Type 2 diabetes mel- litus, cardiovascular disease, obstructive sleep apnea, and others. ${ }^{54}$

Given the close relationship between obesity and psychiatric disorders such as addiction, anxiety, and depression, as well as socioeconomic factors, ${ }^{6}$ patients would have to undergo extensive multidisciplinary evaluation prior to surgery including psychological and socioeconomic evaluation to ensure that appropriate perioperative psychological support is provided so that weight loss gains are sustained. ${ }^{42,61}$ Proposed evaluative end points of a study could include a wide range of biometric markers of obesity such as caloric consumption, resting metabolic rate, and immediate and sustained weight loss, but should also include evaluation of improvements in obesity-related comorbidities and psychological metrics, as well as improvements in overall quality of life (Table 3).

\section{Prader-Willi Syndrome}

Finally, given the severity of hyperphagia, the linked neural reward circuitry dysfunction, and the poor outcomes noted with bariatric surgery, patients with Prader-Willi syndrome (PWS) may represent an additional population of potential trial candidates that may most benefit from

TABLE 2. Contraindications for DBS

\begin{tabular}{l}
\hline Contraindication \\
\hline Recent myocardial infarction \\
\hline Cardiac arrhythmia \\
\hline Cardiac malformation \\
\hline Epilepsy \\
\hline Stroke \\
Degenerative disorder of the nervous system \\
\hline Arterial hypertension or hypotension, not controlled by drugs \\
\hline Autonomic nervous system disorder \\
\hline Endocrinological illnesses \\
\hline Major disturbances in electrolyte imbalance (e.g., due to renal insufficiency or hyperaldosteronism) \\
\hline
\end{tabular}


TABLE 3. DBS for obesity: proposed inclusion criteria and study end points

\begin{tabular}{l}
\hline \multicolumn{1}{c}{ DBS Study for Obesity } \\
\hline Inclusion criteria \\
\hline Failure of bariatric surgery w/ $<50 \%$ of excess weight loss, w/ or w/o BMI $>35 \mathrm{~m} / \mathrm{kg}^{2}$, at 18 months or more after the operation ${ }^{52}$ \\
\hline Diagnosis of food dependence via YFAS criteria ${ }^{23}$ (Table 1) \\
\hline Normal neurological examination \\
\hline Normal head CT scan and cerebral MRI \\
\hline Patient not pregnant \\
\hline Psychiatric evaluation \\
\hline Socioeconomic evaluation \\
\hline Ethics Committee/Institutional Review Board approval \\
\hline Patient informed and gives written consent \\
\hline End points \\
\hline Immediate and sustained weight loss (BMI) \\
\hline Caloric consumption \\
\hline Resting metabolic rate \\
\hline Improvement in YFAS score \\
\hline Amelioration of obesity-related comorbidities \\
\hline Improvement in related psychiatric conditions (depression, anxiety, etc.) \\
\hline Quality of life \\
\hline
\end{tabular}

a DBS intervention tailored around neuromodulation of these very same reward circuits. ${ }^{36}$ Prader-Willi syndrome is caused by a genetic defect resulting in absent expression of several imprinted genes in the 15q11-q13 region from the paternal chromosome $15 .{ }^{4}$ The syndrome is characterized by extreme hyperphagia, obesity, and intellectual disability. Patients with PWS have insatiable appetites and are often morbidly obese. ${ }^{7}$ Nearly 1 of every 3 individuals with PWS are more than $200 \%$ of their ideal body weight, and some have even experienced stomach ruptures from overconsumption. ${ }^{76}$ The metabolic physiology of PWS differs from obesity in normal individuals, such as increased ratio of adiposity to lean mass,${ }^{81}$ decreased total and resting energy expenditure, ${ }^{8}$ and 4 times greater fasting ghrelin levels. ${ }^{33}$ PWS is a difficult to treat syndrome that has not benefited from the most radical medical and surgical interventions. Bariatric surgery, in particular, has been applied toward PWS with limited effectiveness and concerning safety profiles given the increased overall medical comorbidity in this population. ${ }^{69}$

Individuals with PWS consume more food and for longer periods of time than other obese individuals, suggesting a disruption of basic satiety mechanisms and a dysfunctional reward system. ${ }^{48}$ These disruptions have a basis in manifesting as postmeal hyperactivation of specific brain regions involved in the food satiety and reward circuitry, including the hypothalamus, NAc, amygdala, hippocampus, medial prefrontal cortex, orbitofrontal cortex, and insula. ${ }^{35,56,73}$ In functional MRI studies comparing individuals with PWS to obese and healthy-weight controls, individuals with PWS demonstrated higher activity in reward/limbic regions and lower activity in the hypothalamus before eating compared with controls. Thus, patients with PWS may be predisposed to overconsumption due to abnormal basal activity in these brain regions. ${ }^{37}$
PWS represents the pathological intersection between reward and satiety circuitry in the human brain that drives uncontrolled feeding behavior and leads to extreme obese states. Targeting this obese subgroup of individuals may be a reasonable first approach to neuromodulation for obesity given the well-known medical refractoriness of this population. ${ }^{36}$ Clinical trials targeting the $\mathrm{LH}$ are underway for these patients, and future trials of NAc DBS are planned. Specifically, the LH has already been targeted via DBS for obesity $^{90}$ and headache, ${ }^{39}$ and the NAc for OCD, anxiety, addiction, and depression. ${ }^{49}$ We propose that these same targets may be potential targets for DBS in PWS (Fig. 1). ${ }^{36}$

\section{Discussion}

Despite the success of bariatric surgery in the treatment of obesity, there still exists a significant proportion of patients who fail surgical therapy. A neural basis for overeating exhibited in obese patients has been elucidated by both functional imaging as well as DBS studies in animals and limited DBS experience in human patients as well. Specifically, both the hypothalamus (feeding and satiety) and the NAc (reward) have been identified as crucial regulators of food eating behavior that have been demonstrated to be responsive to DBS in treating obesity in animals models. Although upfront costs of DBS are nearly twice that of bariatric surgery, similar degrees of cost savings and cost effectiveness noted in bariatric surgery can likely be obtained with DBS as long as its treatment effects endure, and especially if it is used as an adjunct to bariatric surgery in those patients who experience weight regain.

These patients in whom bariatric surgery ultimately fails likely represent a subpopulation of morbidly obese individuals with a psychiatric basis for their continued excessive food consumption that could lend itself to DBS 
therapy. Patients with PWS may represent an additional treatment indication for DBS given the overlap between the obesity secondary to hyperphagia and the dysregulated reward circuitry observed in this disorder that may make them ideal candidates for DBS. Finally, the efficacy of DBS for obesity will have to be definitively evaluated with a clinical trial that will benefit most from stringent and thoughtful inclusion criteria.

\section{References}

1. Al-Bader I, Khoursheed M, Al Sharaf K, Mouzannar DA, Ashraf A, Fingerhut A: Revisional laparoscopic gastric pouch resizing for inadequate weight loss after Roux-en-Y gastric bypass. Obes Surg [epub ahead of print], 2015

2. Ayyad C, Andersen T: Long-term efficacy of dietary treatment of obesity: a systematic review of studies published between 1931 and 1999. Obes Rev 1:113-119, 2000

3. Bewernick BH, Kayser S, Sturm V, Schlaepfer TE: Longterm effects of nucleus accumbens deep brain stimulation in treatment-resistant depression: evidence for sustained efficacy. Neuropsychopharmacology 37:1975-1985, 2012

4. Bittel DC, Butler MG: Prader-Willi syndrome: clinical genetics, cytogenetics and molecular biology. Expert Rev Mol Med 7:1-20, 2005

5. Brobeck JR: Mechanism of the development of obesity in animals with hypothalamic lesions. Physiol Rev 26:541-559, 1946

6. Brunner EJ, Marmot MG, Nanchahal K, Shipley MJ, Stansfeld SA, Juneja M, et al: Social inequality in coronary risk: central obesity and the metabolic syndrome. Evidence from the Whitehall II study. Diabetologia 40:1341-1349, 1997

7. Butler MG: Prader-Willi syndrome: current understanding of cause and diagnosis. Am J Med Genet 35:319-332, 1990

8. Butler MG, Theodoro MF, Bittel DC, Donnelly JE: Energy expenditure and physical activity in Prader-Willi syndrome: comparison with obese subjects. Am J Med Genet A 143A:449-459, 2007

9. Calle EE, Rodriguez C, Walker-Thurmond K, Thun MJ: Overweight, obesity, and mortality from cancer in a prospectively studied cohort of U.S. adults. N Engl J Med 348:16251638,2003

10. Caplan A: Denying autonomy in order to create it: the paradox of forcing treatment upon addicts. Addiction 103:19191921, 2008

11. Caplan AL: Why autonomy needs help. J Med Ethics 40:301-302, 2014

12. Chang SH, Stoll CR, Song J, Varela JE, Eagon CJ, Colditz GA: The effectiveness and risks of bariatric surgery: an updated systematic review and meta-analysis, 2003-2012. JAMA Surg 149:275-287, 2014

13. Clark SM, Saules KK: Validation of the Yale Food Addiction Scale among a weight-loss surgery population. Eat Behav 14:216-219, 2013

14. Colquitt JL, Pickett K, Loveman E, Frampton GK: Surgery for weight loss in adults. Cochrane Database Syst Rev 8:CD003641, 2014

15. Cremieux PY, Buchwald H, Shikora SA, Ghosh A, Yang HE, Buessing M: A study on the economic impact of bariatric surgery. Am J Manag Care 14:589-596, 2008

16. de Zwaan M, Enderle J, Wagner S, Mühlhans B, Ditzen B, Gefeller O, et al: Anxiety and depression in bariatric surgery patients: a prospective, follow-up study using structured clinical interviews. J Affect Disord 133:61-68, 2011

17. Denys D, Mantione M, Figee M, van den Munckhof P, Koerselman F, Westenberg H, et al: Deep brain stimulation of the nucleus accumbens for treatment-refractory obsessivecompulsive disorder. Arch Gen Psychiatry 67:1061-1068, 2010
18. Expert Panel on the Identification, Evaluation, and Treatment of Overweight in Adults: Clinical guidelines on the identification, evaluation, and treatment of overweight and obesity in adults: executive summary. Am J Clin Nutr 68:899-917, 1998

19. Flegal KM, Carroll MD, Kit BK, Ogden CL: Prevalence of obesity and trends in the distribution of body mass index among US adults, 1999-2010. JAMA 307:491-497, 2012

20. Fletcher PC, Napolitano A, Skeggs A, Miller SR, Delafont B, Cambridge VC, et al: Distinct modulatory effects of satiety and sibutramine on brain responses to food images in humans: a double dissociation across hypothalamus, amygdala, and ventral striatum. J Neurosci 30:14346-14355, 2010

21. Flum DR, Belle SH, King WC, Wahed AS, Berk P, Chapman W, et al: Perioperative safety in the longitudinal assessment of bariatric surgery. N Engl J Med 361:445-454, 2009

22. Frank S, Wilms B, Veit R, Ernst B, Thurnheer M, Kullmann $\mathrm{S}$, et al: Altered brain activity in severely obese women may recover after Roux-en Y gastric bypass surgery. Int J Obes (Lond) 38:341-348, 2014

23. Gearhardt AN, Corbin WR, Brownell KD: Preliminary validation of the Yale Food Addiction Scale. Appetite 52:430436, 2009

24. Gearhardt AN, Yokum S, Orr PT, Stice E, Corbin WR, Brownell KD: Neural correlates of food addiction. Arch Gen Psychiatry 68:808-816, 2011

25. Giacobbe P, Mayberg HS, Lozano AM: Treatment resistant depression as a failure of brain homeostatic mechanisms: implications for deep brain stimulation. Exp Neurol 219:44-52, 2009

26. Glannon W: Consent to deep brain stimulation for neurological and psychiatric disorders. J Clin Ethics 21:104-111, 2010

27. Goodman WK, Foote KD, Greenberg BD, Ricciuti N, Bauer $\mathrm{R}$, Ward H, et al: Deep brain stimulation for intractable obsessive compulsive disorder: pilot study using a blinded, staggered-onset design. Biol Psychiatry 67:535-542, 2010

28. Gracia-Solanas JA, Elia M, Aguilella V, Ramirez JM, Martínez J, Bielsa MA, et al: Metabolic syndrome after bariatric surgery. Results depending on the technique performed. Obes Surg 21:179-185, 2011

29. Grant RA, Halpern CH, Baltuch GH, O’Reardon JP, Caplan A: Ethical considerations in deep brain stimulation for psychiatric illness. J Clin Neurosci 21:1-5, 2014

30. Green E, Jacobson A, Haase L, Murphy C: Reduced nucleus accumbens and caudate nucleus activation to a pleasant taste is associated with obesity in older adults. Brain Res 1386:109-117, 2011

31. Guh DP, Zhang W, Bansback N, Amarsi Z, Birmingham CL, Anis AH: The incidence of co-morbidities related to obesity and overweight: a systematic review and meta-analysis. BMC Public Health 9:88, 2009

32. Halpern CH, Tekriwal A, Santollo J, Keating JG, Wolf JA, Daniels D, et al: Amelioration of binge eating by nucleus accumbens shell deep brain stimulation in mice involves D2 receptor modulation. J Neurosci 33:7122-7129, 2013

33. Haqq AM, Farooqi IS, O'Rahilly S, Stadler DD, Rosenfeld RG, Pratt KL, et al: Serum ghrelin levels are inversely correlated with body mass index, age, and insulin concentrations in normal children and are markedly increased in PraderWilli syndrome. J Clin Endocrinol Metab 88:174-178, 2003

34. Hartman M, Martin AB, Benson J, Catlin A: National health spending in 2011: overall growth remains low, but some payers and services show signs of acceleration. Health Aff (Millwood) 32:87-99, 2013

35. Hinton EC, Holland AJ, Gellatly MS, Soni S, Patterson M, Ghatei MA, et al: Neural representations of hunger and satiety in Prader-Willi syndrome. Int J Obes (Lond) 30:313321,2006 
36. Ho AL, Sussman ES, Zhang M, Pendharkar AV, Azagury DE, Bohon C, et al: Deep brain stimulation for obesity. Cureus 7:e259, 2015

37. Holsen LM, Savage CR, Martin LE, Bruce AS, Lepping RJ, Ko E, et al: Importance of reward and prefrontal circuitry in hunger and satiety: Prader-Willi syndrome vs simple obesity. Int J Obes (Lond) 36:638-647, 2012

38. Hone-Blanchet A, Fecteau S: Overlap of food addiction and substance use disorders definitions: analysis of animal and human studies. Neuropharmacology 85:81-90, 2014

39. Jenkins B, Tepper SJ: Neurostimulation for primary headache disorders: Part 2, review of central neurostimulators for primary headache, overall therapeutic efficacy, safety, cost, patient selection, and future research in headache neuromodulation. Headache 51:1408-1418, 2011

40. Jensen MD, Ryan DH, Apovian CM, Ard JD, Comuzzie AG, Donato KA, et al: 2013 AHA/ACC/TOS guideline for the management of overweight and obesity in adults: a report of the American College of Cardiology/American Heart Association Task Force on Practice Guidelines and The Obesity Society. J Am Coll Cardiol 63 (25 Pt B):2985-3023, 2014

41. Johnson PM, Kenny PJ: Dopamine D2 receptors in addictionlike reward dysfunction and compulsive eating in obese rats. Nat Neurosci 13:635-641, 2010

42. Karlsson J, Taft C, Rydén A, Sjöström L, Sullivan M: Tenyear trends in health-related quality of life after surgical and conventional treatment for severe obesity: the SOS intervention study. Int J Obes (Lond) 31:1248-1261, 2007

43. Kelley AE, Stinus L: Disappearance of hoarding behavior after 6-hydroxydopamine lesions of the mesolimbic dopamine neurons and its reinstatement with L-dopa. Behav Neurosci 99:531-545, 1985

44. Kenny PJ: Reward mechanisms in obesity: new insights and future directions. Neuron 69:664-679, 2011

45. King WC, Chen JY, Mitchell JE, Kalarchian MA, Steffen KJ, Engel SG, et al: Prevalence of alcohol use disorders before and after bariatric surgery. JAMA 307:2516-2525, 2012

46. Laćan G, De Salles AA, Gorgulho AA, Krahl SE, Frighetto L, Behnke EJ, et al: Modulation of food intake following deep brain stimulation of the ventromedial hypothalamus in the vervet monkey. Laboratory investigation. J Neurosurg 108:336-342, 2008

47. Lang AE, Houeto JL, Krack P, Kubu C, Lyons KE, Moro E, et al: Deep brain stimulation: preoperative issues. Mov Disord 21 (Suppl 14):S171-S196, 2006

48. Lindgren AC, Barkeling B, Hägg A, Ritzén EM, Marcus C, Rössner S: Eating behavior in Prader-Willi syndrome, normal weight, and obese control groups. J Pediatr 137:50-55, 2000

49. Lucas-Neto L, Mourato B, Neto D, Oliveira E, Martins H, Correia F, et al: The nucleus accumbens beyond the anterior commissure: implications for psychosurgery. Stereotact Funct Neurosurg 92:291-299, 2014

50. Maggard MA, Shugarman LR, Suttorp M, Maglione M, Sugerman HJ, Livingston EH, et al: Meta-analysis: surgical treatment of obesity. Ann Intern Med 142:547-559, 2005

51. Mann JP, Jakes AD, Hayden JD, Barth JH: Systematic review of definitions of failure in revisional bariatric surgery. Obes Surg 25:571-574, 2014

52. Matsuda M, Liu Y, Mahankali S, Pu Y, Mahankali A, Wang $\mathrm{J}$, et al: Altered hypothalamic function in response to glucose ingestion in obese humans. Diabetes 48:1801-1806, 1999

53. Meany G, Conceição E, Mitchell JE: Binge eating, binge eating disorder and loss of control eating: effects on weight outcomes after bariatric surgery. Eur Eat Disord Rev 22:87-91, 2014

54. Mechanick JI, Youdim A, Jones DB, Garvey WT, Hurley DL, McMahon MM, et al: Clinical practice guidelines for the perioperative nutritional, metabolic, and nonsurgical support of the bariatric surgery patient-2013 update: cosponsored by American Association of Clinical Endocrinologists, The Obesity Society, and American Society for Metabolic \& Bariatric Surgery. Obesity (Silver Spring) 21 (Suppl 1):S1-S27, 2013

55. Meissner W, Schreiter D, Volkmann J, Trottenberg T, Schneider GH, Sturm V, et al: Deep brain stimulation in late stage Parkinson's disease: a retrospective cost analysis in Germany. J Neurol 252:218-223, 2005

56. Miller JL, James GA, Goldstone AP, Couch JA, He G, Driscoll DJ, et al: Enhanced activation of reward mediating prefrontal regions in response to food stimuli in Prader-Willi syndrome. J Neurol Neurosurg Psychiatry 78:615-619, 2007

57. Mink JW, Walkup J, Frey KA, Como P, Cath D, Delong MR, et al: Patient selection and assessment recommendations for deep brain stimulation in Tourette syndrome. Mov Disord 21:1831-1838, 2006

58. Müller UJ, Sturm V, Voges J, Heinze HJ, Galazky I, Heldmann M, et al: Successful treatment of chronic resistant alcoholism by deep brain stimulation of nucleus accumbens: first experience with three cases. Pharmacopsychiatry 42:288-291, 2009

59. Müller UJ, Voges J, Steiner J, Galazky I, Heinze HJ, Möller M, et al: Deep brain stimulation of the nucleus accumbens for the treatment of addiction. Ann N Y Acad Sci 1282:119-128, 2013

60. Murdaugh DL, Cox JE, Cook EW III, Weller RE: fMRI reactivity to high-calorie food pictures predicts short- and long-term outcome in a weight-loss program. Neuroimage 59:2709-2721, 2012

61. Nicolai A, Ippoliti C, Petrelli MD: Laparoscopic adjustable gastric banding: essential role of psychological support. Obes Surg 12:857-863, 2002

62. Passamonti L, Rowe JB, Schwarzbauer C, Ewbank MP, von dem Hagen E, Calder AJ: Personality predicts the brain's response to viewing appetizing foods: the neural basis of a risk factor for overeating. J Neurosci 29:43-51, 2009

63. Pepino MY, Stein RI, Eagon JC, Klein S: Bariatric surgeryinduced weight loss causes remission of food addiction in extreme obesity. Obesity (Silver Spring) 22:1792-1798, 2014

64. Pisapia JM, Halpern CH, Muller UJ, Vinai P, Wolf JA, Whiting DM, et al: Ethical considerations in deep brain stimulation for the treatment of addiction and overeating associated with obesity. AJOB Neurosci 4:35-46, 2013

65. Pisapia JM, Halpern CH, Williams NN, Wadden TA, Baltuch GH, Stein SC: Deep brain stimulation compared with bariatric surgery for the treatment of morbid obesity: a decision analysis study. Neurosurg Focus 29(2):E15, 2010

66. Sallet PC, Sallet JA, Dixon JB, Collis E, Pisani CE, Levy A, et al: Eating behavior as a prognostic factor for weight loss after gastric bypass. Obes Surg 17:445-451, 2007

67. Sani S, Jobe K, Smith A, Kordower JH, Bakay RA: Deep brain stimulation for treatment of obesity in rats. J Neurosurg 107:809-813, 2007

68. Saules KK, Wiedemann A, Ivezaj V, Hopper JA, FosterHartsfield J, Schwarz D: Bariatric surgery history among substance abuse treatment patients: prevalence and associated features. Surg Obes Relat Dis 6:615-621, 2010

69. Scheimann AO, Butler MG, Gourash L, Cuffari C, Klish W: Critical analysis of bariatric procedures in Prader-Willi syndrome. J Pediatr Gastroenterol Nutr 46:80-83, 2008

70. Schlaepfer TE, Cohen MX, Frick C, Kosel M, Brodesser D, Axmacher N, et al: Deep brain stimulation to reward circuitry alleviates anhedonia in refractory major depression. Neuropsychopharmacology 33:368-377, 2008

71. Schoenen J, Di Clemente L, Vandenheede M, Fumal A, De Pasqua V, Mouchamps M, et al: Hypothalamic stimulation in chronic cluster headache: a pilot study of efficacy and mode of action. Brain 128:940-947, 2005 
72. Scholtz S, Miras AD, Chhina N, Prechtl CG, Sleeth ML, Daud NM, et al: Obese patients after gastric bypass surgery have lower brain-hedonic responses to food than after gastric banding. Gut 63:891-902, 2014

73. Shapira NA, Lessig MC, He AG, James GA, Driscoll DJ, Liu Y: Satiety dysfunction in Prader-Willi syndrome demonstrated by fMRI. J Neurol Neurosurg Psychiatry 76:260-262, 2005

74. Stenberg E, Szabo E, Agren G, Näslund E, Boman L, Bylund A, et al: Early complications after laparoscopic gastric bypass surgery: results from the Scandinavian Obesity Surgery Registry. Ann Surg 260:1040-1047, 2014

75. Stephen JH, Halpern CH, Barrios CJ, Balmuri U, Pisapia JM, Wolf JA, et al: Deep brain stimulation compared with methadone maintenance for the treatment of heroin dependence: a threshold and cost-effectiveness analysis. Addiction 107:624-634, 2012

76. Stevenson DA, Heinemann J, Angulo M, Butler MG, Loker J, Rupe N, et al: Gastric rupture and necrosis in Prader-Willi syndrome. J Pediatr Gastroenterol Nutr 45:272-274, 2007

77. Stice E, Yokum S, Bohon C, Marti N, Smolen A: Reward circuitry responsivity to food predicts future increases in body mass: moderating effects of DRD2 and DRD4. Neuroimage 50:1618-1625, 2010

78. Stoeckel LE, Weller RE, Cook EW III, Twieg DB, Knowlton RC, Cox JE: Widespread reward-system activation in obese women in response to pictures of high-calorie foods. Neuroimage 41:636-647, 2008

79. Stroupe KT, Weaver FM, Cao L, Ippolito D, Barton BR, Burnett-Zeigler IE, et al: Cost of deep brain stimulation for the treatment of Parkinson's disease by surgical stimulation sites. Mov Disord 29:1666-1674, 2014

80. Tataranni PA, DelParigi A: Functional neuroimaging: a new generation of human brain studies in obesity research. Obes Rev 4:229-238, 2003

81. Theodoro MF, Talebizadeh Z, Butler MG: Body composition and fatness patterns in Prader-Willi syndrome: comparison with simple obesity. Obesity (Silver Spring) 14:1685-1690, 2006

82. Tomaszewski KJ, Holloway RG: Deep brain stimulation in the treatment of Parkinson's disease: a cost-effectiveness analysis. Neurology 57:663-671, 2001

83. Uusitalo S: Autonomy and DBS treatment for addicts. AJOB Neurosci 4:49-50, 2013

84. Volkow ND, Wang GJ, Fowler JS, Telang F: Overlapping neuronal circuits in addiction and obesity: evidence of systems pathology. Philos Trans R Soc Lond B Biol Sci 363:3191-3200, 2008

85. Volkow ND, Wang GJ, Telang F, Fowler JS, Logan J, Childress AR, et al: Cocaine cues and dopamine in dorsal striatum: mechanism of craving in cocaine addiction. J Neurosci 26:6583-6588, 2006

86. Vucenik I, Stains JP: Obesity and cancer risk: evidence, mechanisms, and recommendations. Ann N Y Acad Sci 1271:37-43, 2012

87. Wadden TA, Faulconbridge LF, Jones-Corneille LR, Sarwer DB, Fabricatore AN, Thomas JG, et al: Binge eating disorder and the outcome of bariatric surgery at one year: a prospective, observational study. Obesity (Silver Spring) 19:12201228,2011

88. Wang BC, Wong ES, Alfonso-Cristancho R, He H, Flum DR, Arterburn DE, et al: Cost-effectiveness of bariatric surgical procedures for the treatment of severe obesity. Eur J Health Econ 15:253-263, 2014

89. Wedin S, Madan A, Correll J, Crowley N, Malcolm R, Karl Byrne T, et al: Emotional eating, marital status and history of physical abuse predict 2-year weight loss in weight loss surgery patients. Eat Behav 15:619-624, 2014

90. Whiting DM, Tomycz ND, Bailes J, de Jonge L, Lecoultre V, Wilent B, et al: Lateral hypothalamic area deep brain stimulation for refractory obesity: a pilot study with preliminary data on safety, body weight, and energy metabolism. J Neurosurg 119:56-63, 2013

91. Wiedemann AA, Saules KK, Ivezaj V: Emergence of new onset substance use disorders among post-weight loss surgery patients. Clin Obes 3:194-201, 2013

92. Wilent WB, Oh MY, Buetefisch CM, Bailes JE, Cantella D, Angle C, et al: Induction of panic attack by stimulation of the ventromedial hypothalamus. J Neurosurg 112:1295-1298, 2010

93. Williams NR, Okun MS: Deep brain stimulation (DBS) at the interface of neurology and psychiatry. J Clin Invest 123:4546-4556, 2013

94. Withrow D, Alter DA: The economic burden of obesity worldwide: a systematic review of the direct costs of obesity. Obes Rev 12:131-141, 2011

95. Ziauddeen H, Farooqi IS, Fletcher PC: Obesity and the brain: how convincing is the addiction model? Nat Rev Neurosci 13:279-286, 2012

\section{Author Contributions}

Conception and design: Halpern, Ho. Acquisition of data: Ho, Sussman, Pendharkar, Bohon. Analysis and interpretation of data: Halpern, Ho, Azagury, Bohon. Drafting the article: Ho, Sussman, Pendharkar, Bohon. Critically revising the article: all authors. Reviewed submitted version of manuscript: Halpern, Ho, Azagury. Approved the final version of the manuscript on behalf of all authors: Halpern.

\section{Correspondence}

Casey H. Halpern, Department of Neurosurgery, Stanford University, 300 Pasteur Dr., Edwards Bldg. R-293, Stanford, CA 94305. email: chalpern@stanford.edu. 